\title{
The Recent Research on Bamboo Reinforced Concrete
}

\author{
Sri Murni Dewi ${ }^{1, *}$, and Devi Nuralinah ${ }^{1}$ \\ ${ }^{1}$ Civil Engineering Department, Brawijaya University, 65145 Malang, Indonesia
}

\begin{abstract}
The paper presents the last research on bamboo reinforced concrete in Brawijaya University Indonesia. Three kinds of structures studied in recent year, the mounting of pegs on reinforcement, the use of lightweight brick to reduce the weight of the beams, and the use the light weight aggregate for bamboo concrete composite frame. All that experiments overcome some problems exist in using bamboo as environmental acceptance structures.
\end{abstract}

\section{Introduction}

Bamboo is available everywhere around the world; some regions in the world continue to use bamboo structures to this day. The energy necessary to produce $1 \mathrm{~m} 3$ per unit of stress projected in practice for materials commonly used in civil construction has been compared with that of bamboo. It was found that for steel it is necessary to spend 50 times more energy than for bamboo. In the production of one tone steel two tons of $\mathrm{CO}_{2}$ is produced. In contrast bamboo plant absorbs $\mathrm{CO}_{2}$ besides producing oxygen. The tensile strength of bamboo is relatively high and can reach $200-300 \mathrm{MPa}$; this turns the use of bamboo attractive as substitute of steel, especially when considering the relation between tensile resistance and specific weight of bamboo which is six times greater than for the steel.

The potential of bamboo as a substitute for steel reinforcement in reinforced concrete beam has been studied by many researchers (Ghavani [1], Kharee [2], Terai [3], and Dewi [4]). Tensile strength of bamboo reinforcement is almost the same with steel reinforcement, but bamboo material is not as ductile as steel material. All those test results showed that the capacity of flexural beam only $56 \%$ of the capacity, if the bamboo reinforcement in beams reached its maximum strength. This low capacity occurs because the bamboo and concrete was not well attached. The recent research head to increase the performance of bamboo reinforced concrete beams by mounted some pegs in the reinforcement. This action aims to strengthen the bond of bamboo and concrete.

As a lightweight material, bamboo is benefit to use as lightweight precast structures. The lightweight structure use for precast beam, to reduce the handling loads. Substitute the steel reinforcement with bamboo is benefit to reduce the weight. For reinforced concrete beams, the concrete in tension area does not require high strength. The concrete can replace

\footnotetext{
*Corresponding author: srimurnid@ub.ac.id
} 
with light weight brick. The current research related to the replacement the tension area of the beam with lightweight precast brick.

Bamboo reinforced concrete has also been used for roof frame structure or bridge girder. Some study has been done (Dewi [5]), the recent research head to use the light weight aggregate for concrete to reduce the weight of precast frame, and use some pegs into the joints of frame.

\section{Bamboo reinforced concrete beam research}

Several series of tests on simply supported bamboo reinforced concrete beams have been studied using normal and lightweight aggregates. Ghavani [1] tests $12 \mathrm{~cm}$ x $30 \mathrm{~cm}$ x300 cm beams with three type reinforcement, steel with reinforcing ratio $0.78 \%$, Bamboo with $3.33 \%$ reinforcing ratio, and bamboo with $5 \%$ reinforcing ratio. The capacity of steel reinforcement beams were $60 \mathrm{kN}$. The capacities of bamboo concrete beam with $3.3 \%$ reinforcement were $20 \mathrm{kN}$. The capacities of bamboo concrete beam with $5 \%$ reinforcement were $30 \mathrm{kN}$. Those result equivalent with bamboo reinforcement strength only $35 \mathrm{MPa}$. It was seen that bamboo concrete beams only has one third capacity.

Karee [2] use $20 \mathrm{~cm} \times 50 \mathrm{~cm} \times 240 \mathrm{~cm}$ beams with varying a/d ratio 1,5-2, and bamboo reinforcement ratio $1 \%-4 \%$.Based on failure load of testing conducted, the equivalent bamboo reinforcement strength varying between $30 \mathrm{MPa}-45 \mathrm{MPa}$. The failure loads varied with the compression strength of the concrete, providing a lower failure load for lower compression strengths. Some beams failed in bond-flexure mode, and others failed in shear mode. Those results indicate the requirement of stirrups in the beams.

Terai [3] use $12 \mathrm{~cm} \times 25 \mathrm{~cm} \times 150 \mathrm{~cm}$ beams with varying shear span and shear reinforcement. They use steel stirrups and PP band with varying distance. The maximum equivalent tensile stress reinforcement was $60-70 \mathrm{MPa}$.

From the entire test above, it is found that the potential strength of bamboo not reached yet. To increase the performance of bamboo reinforced concrete beam some treating needs to increase the attached between bamboo and concrete.

As a lightweight reinforcement, bamboo benefit to combine with others lightweight material especially for precast structures. To eluding reduction of strength, the less strength material put in the unsignificant position like tensin area of flexural beam.

Dewi [5] has use bamboo concrete composite for roof frame structure. The loading test of the frame shows that the failure occurs in the joints of the truss and cracks of concrete in a tension bars. The use of pegs in the tension bar at joints area should increase the capacity of the frame.

The other problems of bamboo concrete composite frame is the weight of frame has obstacle for handling. The weight of frame provided from concrete weight despite that the prior strength of the frame comes from bamboo. The solution of those problem is use the lightweight agregate for the concrete parts.

\section{Increasing bamboo reinforced concrete beam performance by use pegs along reinforcement}

Some research held in Brawijaya University Indonesia, for bamboo reinforced concrete beams. The research related to the effect of adding pegs along the bamboo reinforcement in order to increase the carrying capacity of bamboo reinforced concrete beams. The pegs in the form of bamboo or wood pieces that attached into the reinforcement, is aimed to add the transferred force from the bamboo into the concrete. The addition of pegs along bamboo 
reinforcement aimed at gaining the transfer of force from the concrete to the bamboo reinforcement, thus the capacity of the beam can be increased.

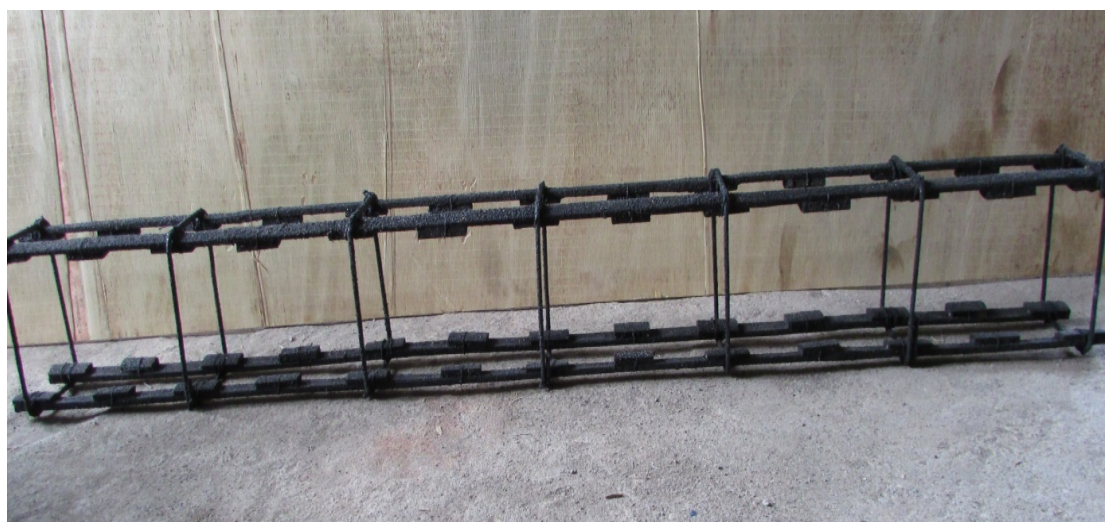

Fig. 1. The pegs along reinforcement.

The research specimen used $18 \mathrm{~cm}$ x $28 \mathrm{~cm}$ x $160 \mathrm{~cm}$ beams. The reinforcement ratio was $0.8 \%$ and $1.6 \%$, and the pegs distance was $6 \mathrm{~cm}$ and $12 \mathrm{~cm}$. Two control beams arranged without pegs for reinforcement ratio $0.8 \%$ and $1.6 \%$. The beam loaded in four point load use a spreader beam as shown in Fig. 2.

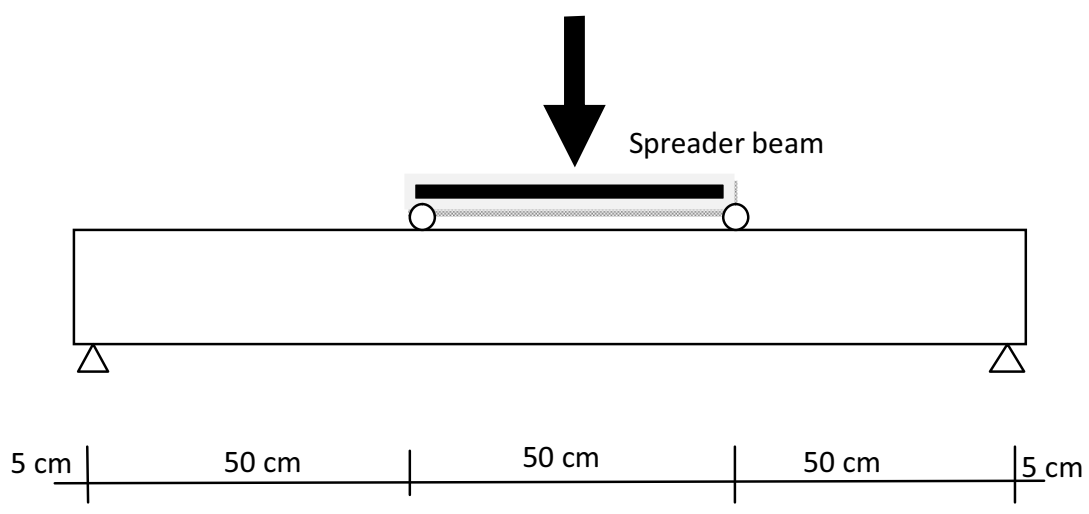

Fig. 2. The loading position.

The load deflection sample for reinforcement ratio $0.8 \%$ presented with pegs distance variation in Fig. 3.

The load deflection curve appearance how the inserting pegs increase the capacity and strain energy of the beams. The average tensile stress of the reinforcement also increased from $45 \mathrm{MPa}$ to $90 \mathrm{MPa}$ reached the strength of the bamboo strength. The collapse started from cracked on beam tensile area and the number of cracks is increased, until finally cracked continues at compression area. For all the 24 test objects do not drop the beam reinforcement, but there are some pegs loose and torn. 


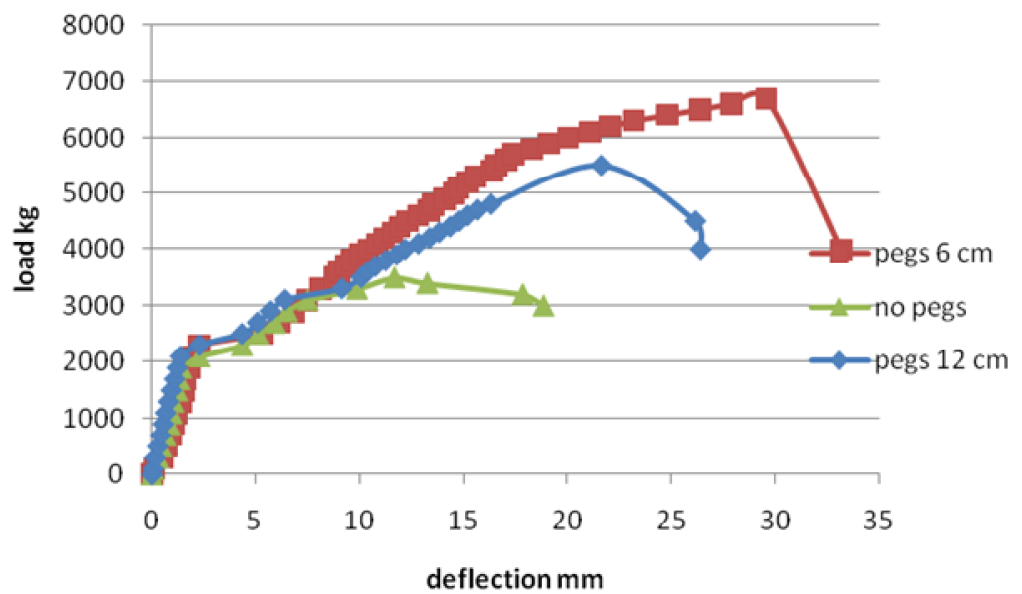

Fig. 3. Load deflection curve with pegs distance variation.

\section{Ultilize bamboo and lightweight brick to reduce the weight of precast concrete beam}

The lightweight structure needed for precast beam to reduce the handling loads. Replacing steel reinforcement with bamboo is benefit to reduce the weight of buildings. In the case of reinforced concrete beams, area of concrete in tension side is unnecessary . This part can be replaced with a lighter material.. Therefore the concrete at drop area replaced with lightweight brick.

This research was conducted through experiment performed on the beam size $16 \mathrm{~cm} \mathrm{x}$ $20 \mathrm{~cm} \times 200 \mathrm{~cm}$ of bamboo reinforced concrete and light brick. The beam test specimen is shown in Fig. 4.

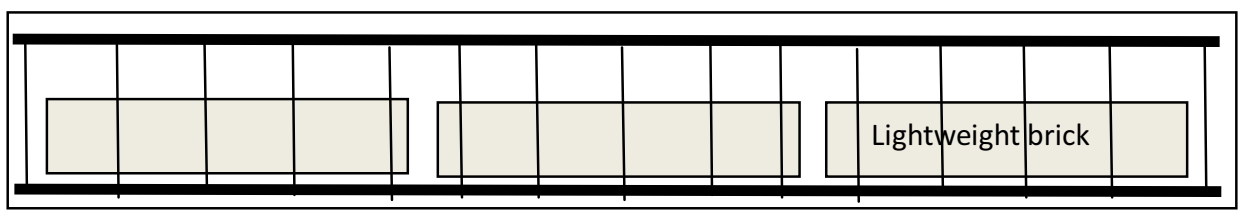

Fig. 4. Bamboo reinforced concrete with lightweight bricks.

The variations of lightweight bricks high were $8.5 \mathrm{~cm}$ and $6.5 \mathrm{~cm}$. The beam compared with the ordinary reinforced concrete beam. The use of lightweight brick could reduce $18 \%$ by weight of the beam. The experiments found that the volume weight of the beam varies between $1900 \mathrm{~kg} / \mathrm{m} 3$ and $2000 \mathrm{~kg} / \mathrm{m} 3$ and there were no significant decreased of the beam strength. For observations crack patterns, it appeared the relationship between the pattern of cracks with the beam strength, the beam with high strength tend to have more number of cracks.

\section{Roof frame from bamboo concrete composite}

Bamboo concrete composite has an axial strength compression and tension very high and very appropriate for structure that dominated with axial force likes frame. This composite 
bamboo concrete frame is useful replace of wood roof frame. The frame should make either in-situ cast concrete or precast concrete.

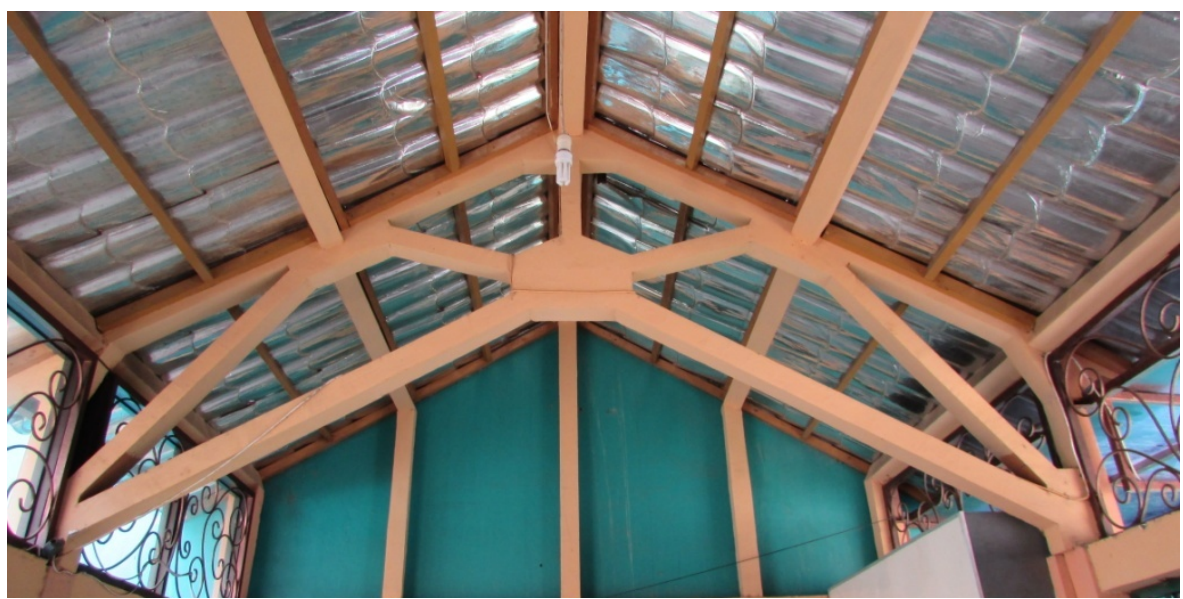

Fig. 5. Roof frame from bamboo concrete composite.

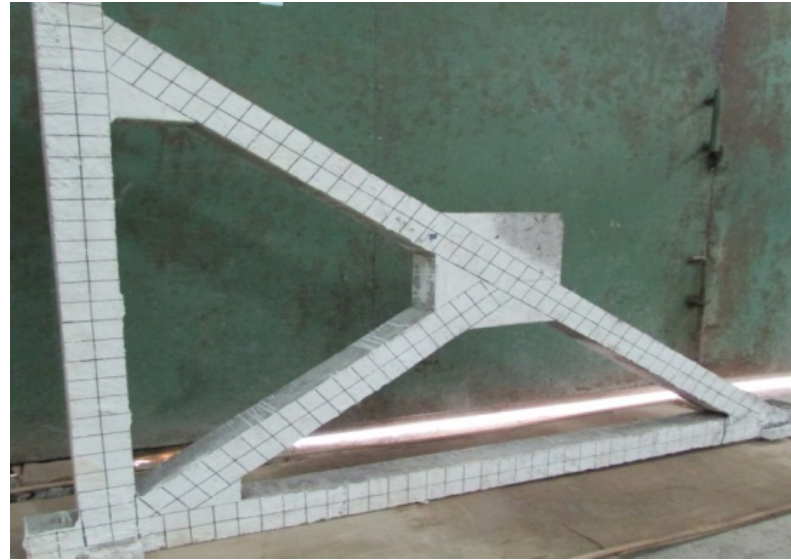

Fig. 6. Precast roof frame from waste brick wall and bamboo reinforcement.

In precast concrete problems, the main obstacle comes from the heavy concrete. The current research is a subtitute the ordinary concrete agregate with lightweight aggregate. For coarse aggregate it were use a waste building brick wall, and for fine aggregate it were substitute a plastic kernel from industrial waste. The composition of those aggregate should reduce the weight by $20 \%$, and only $3 \%$ decrease of strength.

\section{Conclusion}

The use of bamboo for environmentally friendly construction materials, more quickly implemented and added value in terms of cost and environmental sustainability is very interesting to further studied. 
The use of pegs along the beam is able to add tensile load bearing capacity reinforcement. Extra pegs reinforcement adds increase effective stress of $45 \mathrm{MPa}$ to $90 \mathrm{MPa}$.

The use of pegs on reinforcement like hooks on the steel reinforcement will be an opportunity to create a rigid beam-column connection. Another type of pegs was interesting for the next research.

The use of lightweight materials is very advantageous for precast structures and earthquake-resistant structures. The use of construction and industrial waste is benefit in view of environmentally friendly.

The research was held and supported by Ministry of Research Technology and Higher Education Republic of Indonesia.

\section{References}

[1] K. Ghavani, Bamboo as reinforcement in structural concrete elements, Cement and Concrete Composite, 27, 637-649 (2005)

[2] L. Kharee, Performance evaluation of bamboo reinforced concrete beams, Master Thesis, University of Texas, Austin, USA, (2005)

[3] M. Terai and K. Minami, Fracture behavior and mechanical properties of bamboo reinforced concrete members, Japan Procedia Engineering,10, 2967-2972 (2011)

[4] S.M. Dewi, Bamboo use for earthquake resistance housing, Int. Conf. on Earthquake and Disaster Mitigation, Sepuluh November Institute of Technology, Surabaya, Indonesia, (2011)

[5] S.M. Dewi, Roof frame from bamboo concrete composite, J. of Materials Science and Engineering, B-1(1), 113-116 (2011) 